\title{
Liderar, ensinar e apoiar: o papel e a expertise do bibliotecário escolar da Flórida para uma reflexão no contexto brasileiro
}

\author{
To leader, to teach, to support: the function and expertise of Florida school librarians \\ providing a reflection in Brazilian context
}

\begin{abstract}
Adriana Bogliolo Sirihal Duarte
Doutora em Ciência da Informação pela Universidade Federal de Minas Gerais - UFMG. Professora Associada do Departamento de Ciência da Informação da Escola de Ciência da Informação da Universidade Federal de Minas Gerais - UFMG. Professora visitante da School of Information da Florida State University - FSU

E-mail: bogliolo@eci.ufmg.br
\end{abstract}

\section{Resumo}

O artigo apresenta dados sobre os bibliotecários e as bibliotecas escolares do estado da Flórida (Estados Unidos) com o objetivo de provocar uma reflexão sobre a formação do bibliotecário brasileiro. Os dados foram obtidos através de dois métodos: a observação simples, com a participação em uma conferência anual da associação de bibliotecários do estado da Flórida, conhecida como Florida Association of Media in Education (FAME) e a análise documental de vários guias que norteiam os bibliotecários daquele estado: o ExC3EL - conjunto de documentos que apresenta diretrizes para organização e avaliação da biblioteca e de seu programa educativo; o READS - conjunto de documentos que oferece um programa sistematizado de leitura para ser desenvolvido conjuntamente entre professores e bibliotecários; e o FINDS - conjunto de documentos que oferece um programa sistematizado de habilidades a serem desenvolvidas com os alunos a fim de estimular a competência informacional e o aprendizado através da busca de informações. Observou-se que os bibliotecários escolares da Flórida são professores e, na maioria dos casos tem dupla formação, uma graduação em alguma área do conhecimento (com licença para ensinar) e a pós-graduação em biblioteconomia ou ciência da informação. Eles consideram suas principais funções liderar, ensinar e apoiar. No contexto brasileiro, o bibliotecário (graduado em biblioteconomia) tem formação generalista (para atuar em qualquer tipo de biblioteca ou serviço de informação) e, para lidar com crianças e jovens e exercer um papel de visibilidade na escola, certamente teria benefícios de uma formação específica voltada à área educacional.

Palavras-chave: Bibliotecário escolar. Leitura. Competência Informacional. Formação do bibliotecário escolar.

\begin{abstract}
The article presents information about librarians and school libraries of Florida (USA) to raise a reflection on the formation of the Brazilian librarian. The data were obtained through two methods: the observation, with the participation in the annual conference of the Florida Association of Media in Education (FAME), and the documentary analysis of several documents that guide the Libraries of that state: the ExC3EL - a set of documents that presents guidelines for the organization and evaluation of the school library and its educational program; the READS - a set of documents that offers a systematized reading program to be developed jointly between teachers and school librarians; and the FINDS - a set of documents that offers a systematized program of skills to be developed with students in order to stimulate informational literacy and inquiry learning through information researching. It has been observed that Florida school librarians are teachers, and in most cases, have dual backgrounds: a degree in some area of knowledge (with license to teach), and postgraduate in librarianship or information science. They consider their main functions to lead, to teach and to support. In the Brazilian context, the librarian (graduate in librarianship) has general education (to work in any type of library or information service) and, in order to deal with children and young people and to play a role in school, would certainly benefit from a specific training in the educational field.
\end{abstract}

Keywords: School librarian. Reading. Information literacy. School librarian formation.

Bibl. Esc. em R., Ribeirão Preto, v. 5, n. 2, p. 1-20, 2017.

DOI: 10.11606/issn.2238-5894.berev.2017.123160 
Liderar, ensinar e apoiar: o papel e a expertise do bibliotecário escolar da Flórida para uma reflexão no contexto brasileiro

\section{Introdução}

Este artigo tem dois propósitos: apresentar as principais informações extraídas da participação na Conferência Anual da Florida Association of Media in Education (FAME), evento anual promovido por essa associação, ocorrido no período de 19 a 21 de outubro de 2016; e discorrer sobre o Expectations for Collaboration, Collections, and Connections to Enhance Learning: Florida's K-12 Library Program Evaluation Tool (ExC3EL), a ferramenta de avaliação de programa das bibliotecas escolares da Flórida. O objetivo final é buscar a reflexão sobre o seguinte questionamento: qual a vantagem de que o bibliotecário escolar possua também alguma formação como educador? Essa questão foi levantada entre outras que permeiam pesquisa em andamento na Florida State University a fim de buscar perspectivas para a formação do bibliotecário escolar e para a estruturação das bibliotecas escolares no Brasil. Através da análise de documentos e da participação no evento extraiu-se, da experiência do estado da Flórida, subsídios para a reflexão no caso brasileiro.

Os bibliotecários escolares da Flórida se associam localmente à FAME (Florida Association for Media in Education), e nacionalmente à American Association of School Librarians (AASL). O nome da associação estadual explica-se, entre outras razões, devido ao fato de que durante algum tempo as bibliotecas escolares americanas passaram da denominação de school libraries para media centers, buscando dar atenção a outros meios de informação, como resultado da inserção das tecnologias de informação em seu ambiente. Uma vez que incorporaram a mediação da informação através destas tecnologias entre suas funções, os bibliotecários voltaram a entender que school libraryé o nome que melhor denomina seu espaço de trabalho, e vem retomando essa designação. Hoje, no estado da Flórida, encontram-se ambientes com nomes diversos: school library, media center, learning space, learning commons, information commons. Learnning commons e information commons são denominações para designar a combinação entre biblioteca e laboratório de informática em um único serviço completo de aprendizagem, pesquisa e projetos. Normalmente oferecem ambientes para encontros e discussões, tipicamente com pelo menos uma área em que os alunos possam rearranjar os móveis (mesas e cadeiras geralmente com rodinhas e de fácil locomoção) para trabalhos em grupos e/ou palestras e área para estudo individual (MARDIS, 2016, p. 275). Independente da nomenclatura e do arranjo, logo na abertura da $44^{\mathrm{a}}$ Conferência Anual da FAME, uma coisa ficou bastante clara: os bibliotecários da Flórida consideram suas principais funções liderar, ensinar e apoiar. 
Adriana Bogliolo Sirihal Duarte

Os benefícios da liderança do bibliotecário escolar para os alunos e professors encontram-se bem estabelecidos. Quando os bibliotecários escolares assumem papel de liderança, eles contribuem para criar melhores oportunidades de aprendizagem para os estudantes através de sua colaboração com os professores, oferecendo instrução integrada e com uso de tecnologia (EVERHART; JOHNSTON, 2016, p. 1, tradução nossa) ${ }^{1}$.

Além de enfatizar a importância de sua liderança, estes profissionais se consideram, antes de tudo, educadores. Eles ensinam o letramento (ou a competência) informacional (information literacy), isto é, o conjunto de habilidades que tornam os estudantes capazes de "reconhecer quando a informação é necessária e ter a habilidade de localizar, avaliar e utilizar efetivamente a informação necessária" (AMERICAN LIBRARY ASSOCIATION, 2000, p. 2). São eles os especialistas que ensinam às crianças não apenas a localizar, mas também a interpretar e colocar a informação em contexto.

\begin{abstract}
As bibliotecas escolares são ambientes complexos onde a competência informacional é ensinada no contexto do conteúdo curricular. Espera-se, com esta abordagem integrada entre conteúdo e competência informacional, que os jovens usuários de informação apliquem habilidades específicas de informação às suas tarefas de aprendizagem. O conteúdo da questão [solicitada pelo professor] deriva do currículo escolar e gera padrões que propiciam este tipo de aprendizagem baseada em problemas. A colaboração entre bibliotecário escolar e professor promove apoio aos usuários no ambiente rico em informações e tecnologia da biblioteca escolar. A intenção é que a biblioteca da escola funcione como um laboratório para que os usuários construam o conhecimento enquanto usam habilidades como ferramentas de gerência da informação dentro das tarefas de aprendizagem que estruturam as questões (GORDON, 2011, p. 162). ${ }^{2}$
\end{abstract}

Desse modo, cabe aos bibliotecários escolares ensinar aos alunos as habilidades de localizar as informações [de que necessitam para resolverem suas questões] na coleção física e nas tecnologias de informação disponíveis no ambiente da biblioteca, bem como apoiar os professores na elaboração das atividades, trabalhando de maneira colaborativa.

Participar da FAME 2016 foi uma experiência enriquecedora. Estavam presentes mais de 700 bibliotecários escolares de diferentes distritos da Flórida. Embora os organizadores do evento estivessem contentes com o elevado número de participantes, uma de suas metas é

\footnotetext{
${ }^{1}$ Original em inglês: The benefits of school librarian leadership to both students and teachers have been well established. When school librarians take on leadership roles, they contribute to creating better learning opportunities for students through the librarians' collaborating with teachers, providing engaging instruction, and integrating technology (EVERHART, JOHNSTON, 2016, p.1).

${ }^{2}$ Original em inglês: School libraries are complex environments where information literacy is taught in the context of curriculum content. This integrated approach of academics and information literacy sets the expectation that young information users will apply targeted information skills to their learning tasks. The content of inquiry derives from school curricula and state standards that are conducive to this kind of problem based learning. The collaboration between school librarian and classroom teacher provides support to users in the information and technology rich environment of the school library. The intent is that the school library will function as a laboratory for users to construct knowledge as they use information skills as information management tools within the learning tasks that structure the inquiries (GORDON, 2011, p. 162).
} 
Liderar, ensinar e apoiar: o papel e a expertise do bibliotecário escolar da Flórida para uma reflexão no contexto brasileiro

aumentar significantemente o número de associações à entidade. Se nos anos anteriores a participação na conferência ficava na casa dos 400 inscritos $^{3}$, demonstrando um efetivo aumento esse ano, tal número não reflete ainda a comprometimento desejado pela classe. Eles buscam maior engajamento de seus colegas e mais trabalho em equipe. Para compreender-se a extensão disso, é preciso entender que a Flórida é o segundo estado americano em bibliotecas escolares. Para gerenciá-las, o estado é dividido em 5 regiões e cada região em vários distritos escolares, como mostra a FIG. 1.
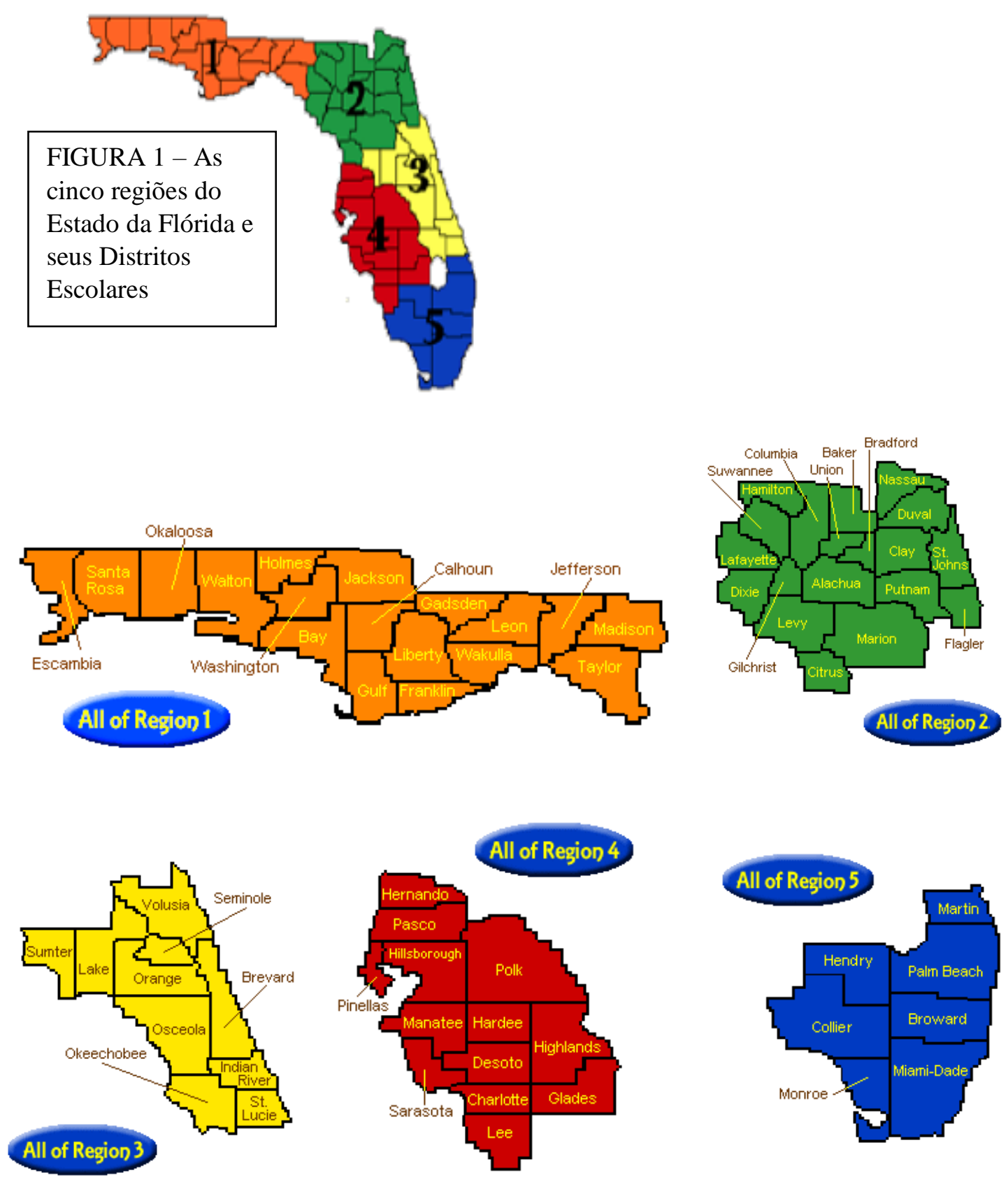

Fonte: Site oficial da FAME: http://www.floridamediaed.org/about.html . Acesso em: 25 out. 2016.

\footnotetext{
${ }^{3}$ Informação obtida oralmente através dos organizadores do evento.
} 
Outro ponto importante para se compreender o ponto de vista dos bibliotecários participantes deste evento é conhecer sua formação. Para se tornar um bibliotecário escolar no estado da Flórida, todo profissional precisa necessariamente ter experiência de ensino (ou seja ter sido professor licenciado na escola) e ter um mestrado em biblioteconomia escolar (school library) ${ }^{4}$. Essa formação - tanto a experiência em ensino quanto o mestrado em Biblioteconomia ou Ciência da Informação não é exigida, no entanto, em todos os estados americanos. A graduação em algum curso aprovado pela ALA é suficiente em alguns estados. Segundo dados de 2010, 22\% dos bibliotecários escolares americanos eram bacharéis, 58,7\% tinham titulação de mestre e 4,9\% grau de doutorado (os demais tinham alguma graduação sendo que uma porcentagem ínfima $(0,3 \%)$ tinha apenas o ensino médio completo ou incompleto $)^{5}$.

Independente da titulação, cada palestrante bibliotecária(o) na $44^{\mathrm{a}}$ Conferência Anual da FAME, comumente se apresentava dizendo que sua experiência profissional era de $\mathrm{x}$ anos como bibliotecária(o) escolar mas que, antes disso, tinha sido professor(a) por y anos (vale comentar que, entre as palestras que assisti, esse y nunca foi inferior a 8 anos). Todos demonstraram, em seu modo de se expressar, que consideram ser bibliotecário mais importante que ser professor, como se o bibliotecário escolar fosse um professor com um algo a mais, um "professor mais importante", com uma missão "mais nobre", mas cuja principal função continua sendo a de ensinar.

E se a principal função é a de ensinar, o programa da biblioteca escolar se vincula intimamente com a garantia do ensino, ou seja, com o propósito da biblioteca atuar como espaço de promoção de leitura e de atividades que promovam a competência informacional do aluno, oferecendo-lhe oportunidades para construir conhecimento de forma lúdica, interativa e dinâmica. Isso se reflete no instrumento de avaliação do programa da biblioteca escolar na Flórida, o ExC3EL. De acordo com ele, uma biblioteca pode ser avaliada como introdutória, em desenvolvimento, avançada ou exemplar em cada um dos quesitos analisados, a saber: instrução (em primeiro lugar, incluindo competência informacional e instrução baseada em questionamentos; instrução que promova o transletramento em múltiplas plataformas;

\footnotetext{
${ }^{4}$ Até o ano passado o Estado da Flórida tinha um convênio com as universidades que ofereciam o curso de mestrado aprovado pela American Library Association (ALA) e aceitava o mestrado em bibliotecomia escolar como a titulação para o exercício da profissão. Atualmente há um processo de renegociação e, para se tornar bibliotecário escolar, o profissional tem de se submeter individualmente a um exame de certificação promovido pelo estado após ter concluído algum curso de mestrado em Biblioteconomia ou Ciência da Informação aprovado pela American Library Association (ALA).

${ }^{5}$ Disponível em: http://www.teacher.org/career/school-librarian/. Acesso em: 25 out. 2016.
} 
Liderar, ensinar e apoiar: o papel e a expertise do bibliotecário escolar da Flórida para uma reflexão no contexto brasileiro

apreciação literária e instrução baseada na literatura; parceria e colaboração com a instrução e o ensino); apoio curricular (incluindo promoção e orientação à leitura; grau de integração nas sessões de desenvolvimento profissional e grau de participação no plano de desenvolvimento escolar); gerenciamento de recursos (item em que são avaliados a coleção, organização, aquisição e manutenção); administração de programa (item em que se avaliam pessoal, orçamento, acesso, website; tecnologias no sentido de acesso a computadores e periféricos, acesso a televisores e multimídias; OPACs via intranet e internet); ambiente (em que se avalia o espaço físico, móveis, estética, distribuição do espaço) e promoção (em que se analisa o envolvimento da biblioteca escolar com a comunidade de aprendizagem e com os pais).

Ao longo deste artigo serão apresentados, portanto, itens observados durante o congresso da FAME no sentido de se obter um perfil senão do bibliotecário escolar estadunidense, ao menos do bibliotecário escolar do estado da Flórida. Tentar compreender o perfil deste bibliotecário escolar (através da avaliação de sua participação no congresso) e o que se considera importante na biblioteca escolar de sucesso no estado da Flórida (através da análise do Exc3EL) é a estratégia utilizada nesse ensaio para se responder aos questionamentos que norteiam nossa proposta: 1. O que é importante para uma biblioteca escolar brasileira? 2. A formação complementar do bibliotecário escolar em educação é vantajosa para se alcançar a biblioteca escolar de excelência?

\section{O bibliotecário escolar e as tecnologias de informação}

A conferência da FAME tem a duração de três dias, sendo o primeiro deles praticamente dedicado a workshops pré-conferência, para os quais deve-se fazer inscrição e pagamento à parte. Esse ano foram oferecidos cinco workshops, um de dia inteiro (seis horas) para novos bibliotecários, com o título convidativo "Seja esperto, supere, vença: sobreviva ao seu primeiro ano (ou dois!) como bibliotecário escolar ${ }^{6 ”}$. Os outros quatro (dois de manhã e dois à tarde) tiveram três horas de duração cada e versaram sobre diferentes tecnologias de informação aplicadas à biblioteca escolar em contextos diversos: storytelling, pesquisa, educação em informática, programação de computadores. Importante perceber que de cinco workshops, quatro tinham como temática o uso de tecnologias da informação (TI) na biblioteca escolar. Isso já aponta para um fato que pode ser ratificado ao longo de todo o evento: o bibliotecário

\footnotetext{
${ }^{6}$ New Librarians Workshop: Outwit-Outplay-Outlast: Surviving Your First Year (or Two!) as a School Librarian
} Bibl. Esc. em R., Ribeirão Preto, v. 5, n. 2, p. 1-20, 2017. 
escolar, em seu papel de liderança, considera essencial ser o promotor da TI no ambiente da escola.

De fato, nos dias seguintes, houve sessões que comprovaram isso: a Flórida vem passando por uma fase de transição através da implementação de legislação que obriga a inserção de tecnologia digital nas escolas e são os bibliotecários quem estão lançando os projetos nas escolas que garantem o cumprimento desta lei. Foi apresentado, por exemplo, o relato de experiência Going Digital, em que bibliotecárias de um distrito (Orange County, décimo maior distrito escolar do país e quarto da Flórida) contaram como propuseram o projeto piloto "um-para-um" (one-to-one), em que cada estudante das escolas do distrito (o piloto começou com nove escolas no primeiro ano e mais dez no segundo ano) receberia um dispositivo (ipad, chromebook, windows device ou mac) para usar durante todo o ano letivo. Detalharam desde como foi treinar os professores para usar os dispositivos, propor atividades didáticas através deles, adotar e-books nestes suportes, etc., até como foi reunir-se com os pais de alunos para explicar como funcionaria o projeto, o que ocorreria se o dispositivo em poder do aluno estragasse, etc. O uso de diferentes tecnologias foi proposital, já que se tratava de piloto e buscava-se comparar qual a interface seria mais adequada para professores e alunos. Concluiram que o estado (pagador) não estava preocupado em qual seria o economicamente mais viável, desde que o escolhido fosse funcional, no sentido de suportar todas as demandas, ou seja, comportar os programas educacionais (software e livros) necessários para o aprendizado dos alunos. Ressaltou-se, o tempo todo, na apresentação, que a condução de todo o projeto foi feita por bibliotecários escolares, ou seja, que é papel desse profissional atuar como líder na inserção das tecnologias de informação em todo o ambiente da escola (não apenas na biblioteca) promovendo, assim, a competência informacional (information literacy). Finalmente, descreveram que o próprio layout da biblioteca vem mudando com a efetivação do projeto um-para-um. Se antes as bibliotecas do distrito preocupavam-se em ter estações de trabalho para que os alunos pudessem acessar a informação digital, agora os alunos já vem para a biblioteca trazendo seus próprios dispositivos. Isso siginifca que as estações de trabalho que tinham este fim estão sendo aos poucos retiradas do ambiente da biblioteca, provendo assim mais espaço para o ambiente de trabalho colaborativo e em grupo, e a grande preocupação está sendo em oferecer tomadas para que os alunos possam recarregar seus dispositivos durante o uso.

O primeiro dia do evento encerrou com um sessão de pôsteres e a recepção de abertura do hall de exibição, onde empresas diversas expunham seus produtos para bibliotecas. Ali 
Liderar, ensinar e apoiar: o papel e a expertise do bibliotecário escolar da Flórida para uma reflexão no contexto brasileiro

podiam-se encontrar inúmeras editoras, tanto didáticas quanto de livros de literatura infantojuvenil; empresas de móveis e utensílios para bibliotecas e muitas, muitas empresas de tecnologia: software de todos os tipos, de gestão de bibliotecas, de compartilhamento de leitura, programas educativos, e-books, além de scanners, impressoras 3-D, mini-robôs para ensino de programação de computadores, etc.

A sessão de abertura do evento ocorreu no segundo dia, logo pela manhã, e também versou sobre a temática de tecnologia. Com o título "Liderança Digital: mudando paradigmas para tempos de mudança" ${ }^{7}$, a tônica foi mostrar o papel e a penetração das mídias sociais na biblioteca e na educação e demonstrar a importância de se focar no aprendizado e no pensamento crítico do aluno. O caminho sugerido foi o de se ensinar através do questionamento, propondo ao aluno perguntas em que ele não possa simplesmente "googlar" para obter as respostas. Se o aluno puder encontrar facilmente aquilo de que precisa, ele jamais exercitará a capacidade de pesquisa e de pensamento crítico, e a biblioteca escolar perderá sua razão de existir.

\begin{abstract}
Letramento em informação e em tecnologia são, claramente, "o conjunto de habilidades básicas do século 21 ”. (...) Informação e tecnologia afetam todas as pessoas em todos os possíveis ambientes - educação, serviço público, e negócios. Educação é fundamentalmente baseada em informação. Isto é, todos os aspectos do ensino e aprendizagem requerem colher, processar e comunicar informação. No passado, na educação, havia uma dependência em um recurso de informação primária: o livro didático. Mas isso está mudando rapidamente devido em grande parte à explosão das tecnologias de informação e das informações em rede. O mesmo é verdade no serviço público - os cidadãos estão cada vez mais recorrendo a fontes eletrônicas e serviços de informação baseados na Internet. E as empresas bemsucedidas de hoje são aquelas que se concentram em usos significativos de informação e tecnologia e contratam funcionários que são capazes de aplicar a tecnologia para uma variedade de situações (EISENBERG, 2008, p. 39, tradução nossa) ${ }^{8}$.
\end{abstract}

Muitas outras palestras do evento discutiram a questão das tecnologias de informação, quer seja demonstrando novos software que podem ser úteis na biblioteca escolar, quer seja apresentando relatos de experiência de uso de tecnologias em atividades na biblioteca. Uma mesa redonda discutiu o uso de $e$-books na biblioteca escolar. Participaram várias bibliotecárias

\footnotetext{
${ }^{7}$ Digital Leadership: Changing Paradigms for Changing Times

${ }^{8}$ Original em inglês: Information and technology literacy is clearly the "basic skills set of the 21 st century." (...) Information and technology affects every person in every possible setting - education, public service, and business. Education is fundamentally information-based. That is, every aspect of learning and teaching requires the gathering, processing, and communication of information. In the past in education, there was a reliance on one primary information resource: the textbook. But this is rapidly changing due in large part to the explosion in information technology and networked information. The same is true in public service - citizens are increasingly turning to web-based, electronic sources and services for information. And, today's successful companies are those that focus on meaningful uses of information and technology and hire employees who are able to apply technology to a range of situations (EISENBERG, 2008, p. 39).
} 
em cujas bibliotecas já há e-books na coleção e uma representante de editora de $e$-books de livros didáticos. Algumas bibliotecas já utilizam e-books há vários anos, outras estão iniciando agora, justamente por causa da lei que propõe que todas as escolas públicas da Flórida adotem livros didáticos digitais a partir do ano letivo $2015-16^{9}$ e que estas escolas gastem pelo menos $50 \%$ de seu orçamento em livros didáticos com livros digitais a partir desta data. Algumas escolas possuem livros eletrônicos também de literatura, outras apenas livros didáticos. Houve relatos de bibliotecárias que possuem centenas e até milhares (mais de 4 mil) de títulos em sua coleção.

Os principais pontos debatidos acerca dos e-books foram os diferentes modelos de compra (single access, multi-user access, limited checkout, limmited time-frame), outras fontes de $e$-books (foram citadas a Florida Electronic Library e o Projeto Gutemberg entre outros), as taxas de hospedagem (discutiu-se as vantagens em se hospedar os livros em servidores próprios ou nos da editora) e os impedimentos para a compra de $e$-books. Entre estes, falou-se bastante a respeito do inconveniente de que cada editora tem utilizado uma plataforma diferente, o que dificulta o trabalho do leitor, que não tem um ambiente ou interface único; tem que se adaptar a diferentes interfaces, além de possuir diferentes contas e senhas. Ficou evidente que, embora não acreditem no fim do livro impresso, pelo menos por enquanto, os bibliotecários escolares da Flórida já convivem no ambiente híbrido e os alunos já utilizam o e-book no seu cotidiano.

\section{O bibliotecário escolar e o autor}

Com exceção de três grandes palestras - a de abertura, a denominada sessão geral e a de encerramento - em que todos os participantes do evento se reuniram num mesmo local simultaneamente, as demais sessões do evento eram denominadas sessões concorrentes, pois havia mais de uma coisa acontecendo ao mesmo tempo e cabia ao expectador optar por uma delas. A palestra de abertura, conforme já apresentado, versou sobre liderança digital. Os palestrantes convidados para as duas outras grandes seções eram, no entanto, autores de livros infanto-juvenis.

Além de comparecerem ao lúdico "speed dating with the authors" que aconteceu no primeiro dia do evento, uma brincadeira em que as(os) bibliotecárias(os) tomavam um coquetel

\footnotetext{
${ }^{9} \mathrm{O}$ ano letivo americano começa em agosto e termina em junho do ano seguinte.
} 
Liderar, ensinar e apoiar: o papel e a expertise do bibliotecário escolar da Flórida para uma reflexão no contexto brasileiro

com quinze autores americanos e trocavam flores de papel com bilhetes entre si, estes e outros autores estiveram presentes em todas - sem exceção - todas as sessões do evento.

Na seção de abertura, antes da palestra convidada, houve a premiação do $33^{\circ}$ Sunshine State Young Readers Award (SSYRA). O SSYRA é um programa para motivar estudantes do ensino fundamental ( $3^{-}$ao $8^{\circ}$ anos, aproximadamente 8 a 13 anos de idade) a ler independentemente e por prazer, e a ler livros que estejam abaixo, no e acima do seu nível de leitura, com o objetivo de melhorar sua fluência de leitura. Um comitê de bibliotecários escolares seleciona os livros participantes a cada ano. Para isso, lêem cerca de 250 livros, dos quais selecionam 15. Os alunos interessados em participar do programa fazem a leitura dos 15 e votam naquele que preferiram. A votação fica aberta pelo período de um ano, mas as bibliotecas das escolas precisam estar cadastradas para que seus alunos possam participar. A autora do livro vencedor do ano (2015-16, Sarah Weeks, com o livro Pie) foi convidada a receber sua premiação na seção de abertura da Conferência de 2016.

A conferência geral do evento foi de responsabilidade de um autor, poeta e educador: Kwame Alexander, vencedor da medalha Newbery 2015 com o livro The Crossover e autor de 21 livros. Modesto, divertido e interagindo sempre com o público, ele contou como começou a escrever poemas: se apaixonou por uma garota na época em que não existiam celulares e lhe fez a seguinte proposta: como não tenho dinheiro para te convidar para sair para um lugar chique e tenho medo de que você recuse meu convite, posso te enviar um poema por dia? E, durante os 365 dias de um ano, enviou-lhe, por fax, um poema. E foi, assim, aperfeiçoando sua escrita e ganhando a afeição a moça! Em seguida, lembrou que só tem leitores graças aos bibliotecários. Se não fossem eles, que indicam seus livros, não se tornaria conhecido.

Também a palestra de encerramento foi feita por um autor, Jay Asher, que já tem seu best seller traduzido inclusive para o português: Os 13 porquês. O livro conta a história de um garoto que, ao chegar em casa da escola, encontra em sua porta um pacote com sete fitas cassete. No lado A da primeira fita ouve sua ex-colega, que cometera suicídio duas semanas antes, explicar que ele encontrará, em cada gravação (cada lado de uma fita) um motivo que a levou a tomar a decisão de se matar. Cabe ao garoto ouvir tudo. $\mathrm{O}$ autor conta de como não foi um bom aluno, mas sempre um ótimo leitor - e agradece aos bibliotecários por isso. Conta de sua experiência percorrendo 50 estados americanos no tour contra o bullying, resultante deste seu livro. Descreve relacionamentos com ouvintes de suas palestras e com seus leitores. Conta 
Adriana Bogliolo Sirihal Duarte

como se inspirou para escrever outros livros e, o tempo todo, agradece aos bibliotecários pelo seu sucesso.

Nos demais horários do evento, conforme explicado, ocorreram sessões concorrentes. Várias palestras foram oferecidas simultaneamente, todas com duração de 50 minutos (e 10 minutos entre uma e outra). Ao público coube a escolha. E, no leque de escolhas, pelo menos uma, senão duas, sempre foi o depoimento de um autor de literatura americano. Ou seja, caso desejasse, um bibliotecário escolar poderia ter ficado o evento inteiro apenas ouvindo autores.

Os bibliotecários da Flórida são leitores. Eles leem para fazer indicação de leitura para seus usuários. Eles conhecem os autores que estão publicando em seu país: conhecem sua obra, conhecem sua biografia. E procuram conhecê-los pessoalmente. Tiram fotos com eles e pegam autógrafos em seus livros com sorrisos estampados nos rostos. Fui testemunha disso diversas vezes no evento.

Além disso, promovem eventos e premiações para fazer com que seus usuários sejam também leitores. Além do SSYRA, destinado a motivar a leitura entre os alunos do $3^{\mathrm{o}}$ ao $8^{\mathrm{o}}$ ano, existem o SSYRA Jr. para crianças menores e o Florida Teens Read para alunos do ensino médio ( $9^{\circ}$ a $12^{\circ}$ anos). Os autores americanos consideram ganhar essas premiações muitas vezes mais importante que outras, ainda que mais renomadas. Ter seu livro escolhido como vencedor no Florida Teens Read Award, por exemplo, significa ter atingido realmente o público alvo desejado, o leitor juvenil, ter despertado seu interesse na leitura daquele livro. Significa ter ganhado do shopping, do(a) namorado(a), do jogo eletrônico, do computador, da internet - não apenas dos autores e livros concorrentes!

A participação dos autores no congresso da FAME e o carinho mútuo entre eles e os bibliotecários demonstrou a importância dada à leitura pelo bibliotecário escolar e a respectiva importância dada ao bibliotecário pelos profissionais da escrita. 
Liderar, ensinar e apoiar: o papel e a expertise do bibliotecário escolar da Flórida para uma reflexão no contexto brasileiro

\section{O bibliotecário escolar e o ensino}

Ainda durante o evento foram premiadas aquelas bibliotecas escolares consideradas Florida Power Libraries. Para concorrer a essa premiação, a biblioteca escolar tem de se inscrever e preencher alguns requisitos, que devem ser comprovados através de um pequeno vídeo de até cinco minutos e de um portfolio ${ }^{10}$. Os principais requisitos são aqueles estabelecidos pelo documento ExC3EL. Portanto, serão premiadas bibliotecas avançadas ou exemplares conforme as diretrizes esperadas para colaboração, coleção e conexões da ferramenta de avaliação de bibliotecas escolares da Flórida.

No que concerne a bibliotecas escolares, o Departamento de Educação da Flórida apresenta três conjuntos de documentos: FINDS, READS e ExC3EL: o primeiro fornece um modelo de programa de competência informacional na biblioteca escolar; o segundo apresenta diretrizes de leitura para programas colaborativos entre biblioteca escolar e sala de aula; e o terceiro é uma ferramenta de autoavaliação da própria estrutura da biblioteca escolar envolvendo todos os seus programas e objetivos.

FINDS é um acrônimo para Focus, Investigate, Note, Develope e Score. A proposta do modelo resume-se em focar na informação necessária; investigar recursos para buscar pela resposta; notar e avaliar fatos e ideias para responder à questão; transformar informação em conhecimento para apresentação; e avaliar a apresentação e o processo de busca. Há uma série de documentos que indicam ao aluno o que se espera dele e ao bibliotecário como contribuir para cada aluno, em cada fase do ensino, para que ele adquira a competência necessária naquele momento. É um excelente instrumento para o trabalho colaborativo com o professor.

READS é um acrônimo para Read, Explore, Analyze, Develope e Score. De forma semelhante ao modelo anterior, as diretrizes propõem ler como uma atividade pessoal; explorar as persnonagens, história e premiações dos trabalhos criativos (livros); analizar a estrutura e características estéticas dos trabalhos criativos (livros); desenvolver um produto baseado na literatura; e avaliar o progresso na leitura. Novamente, um conjunto de documentos, a grande maioria para serem utilizados pelo bibliotecário escolar, alguns para o aluno, estão disponibilizados pelo Departamento de Educação da Flórida ${ }^{11}$.

\footnotetext{
${ }^{10}$ Exemplos de vídeos de bibliotecas premiadas podem ser vistos em Outstanding School Library Programs: http://www.flpowerlibraries.com/fpls-documents.html. Acesso em: 02 nov. 2016.

${ }^{11}$ Disponível em: http://www.fldoe.org/academics/standards/subject-areas/library-media-services-instructional-t/ Acesso em: 02 nov. 2016.
} 


\title{
A ferramenta ExC3EL fornece
}

\begin{abstract}
um continuum para o desenvolvimento de programas de bibliotecas escolares capazes de aprimorar e apoiar a agenda educacional das escolas. Os programas de bibliotecas escolares de qualidade fornecem ambientes acolhedores e ricos em recursos que suportam múltiplos letramentos, cultivam uma cultura de investigação e apreciação literária, e incentivam a exploração ética e independente de informações e ideias (ExC3EL, [20--], tradução nossa) ${ }^{12}$.
\end{abstract}

Os seis itens avaliados pelo ExC3EL são os mesmos verificados no vídeo e portfolio submetidos à avaliação do Florida Power Libraries. Nenhuma biblioteca escolar é obrigada a submeter-se a um ou outro, seja o instrumento de avaliação, seja candidatar-se à premiação. Conforme já explicado, em cada um dos seis itens, o programa de avaliação sinaliza o que cada biblioteca deve ter para se classificar um dos seguintes níveis: introdutória, em desenvolvimento, avançada ou exemplar. Os seis itens avaliados são:

1. instrução: visa verificar, em cada nível, o quanto o programa da biblioteca melhora o resultado dos alunos por meio de um programa educacional planejado sistematicamente e colaborativamente;

2. apoio curricular: visa avaliar o quanto o programa da biblioteca melhora o resultado dos alunos através do apoio a todas as facetas do programa educacional;

3. gerência de recursos: visa verificar se o programa da biblioteca oferece recursos apropriados, corretos e atuais em todos os formatos para atender às necessidades da comunidade;

4. administração de programa: tem o objetivo de avaliar o quanto os processos e recursos tecnológicos aprimoram o aprendizado e auxiliam como infraestrutura para administrar um programa de biblioteca adequadamente qualificado e consolidado;

5. ambiente: avalia em que nível o programa de biblioteca realmente provê um ambiente convidativo, acessível e estimlante para uso individual e em grupo que compartilhe os recursos entre a comunidade de aprendizagem;

6. promoção: verifica de que formas o programa de biblioteca e suas iniciativas são promovidos através da comunidade de aprendizagem.

\footnotetext{
12 Original em inglês: The ExC3EL Rubric provides a continuum for developing outstanding school library media programs that enhance and support the school's educational agenda. Quality library media programs provide a welcoming, resource-rich environment that supports multiple literacies cultivates a culture of inquiry and literary appreciation, and encourages the independent, ethical exploration of information and ideas. Disponível em: www.fldoe.org/core/fileparse.php/7564/urlt/evaluationrubric.pdf. Acesso em: 08 nov. 2016.
} 
Liderar, ensinar e apoiar: o papel e a expertise do bibliotecário escolar da Flórida para uma reflexão no contexto brasileiro

Uma biblioteca escolar que deseje fazer uma autoavaliação encontra disponível, além do documento que mostra o que é indicado para classificar-se em cada nível (ExC3EL Evaluation Rubric ${ }^{13}$ ), uma planilha para preencher e pontuar seu programa (ExC3EL Evaluation Rubric Scoring Sheet ${ }^{14}$ ) e outra para criar um planejamento estratégico para o seu aprimoramento durante um ano letivo (ExC3EL Improvement Plan ${ }^{15}$ ).

Os dois primeiros itens avaliados no documento estão diretamente ligados à função educativa da biblioteca escolar, e focaremos nossa atenção neles. O quadro 1 a seguir reproduz os componentes avaliados no tópico instrução para cada um dos níveis de classificação do programa de biblioteca. De acordo com a planilha de avaliação, a biblioteca deve atribuir-se a pontuação 1 no item em que se considerar introdutória, 2 quando se considerar em desenvolvimento, 3 quando se considerar avançada e 4 se julgar-se exemplar. Portanto, como o tópico instrução é formado de 4 componentes, a pontuação mínima neste tópico será 4 e a máxima 16, podendo haver variações intermediárias. A média do tópico deve ser calculada através da divisão deste total por 4 .

O que se pode observar é que não se espera que uma biblioteca introdutória desenvolva um programa instrucional. Mas tão logo ela comece a entrar em desenvolvimento, deve passar a se preocupar com seu programa educativo. Quanto mais bem estabelecida a biblioteca, mais

\footnotetext{
${ }^{13}$ Disponível em http://www.fldoe.org/core/fileparse.php/7564/urlt/evaluationrubric.pdf. Acesso em: 08 nov. 2016.

${ }^{14}$ Disponível em http://www.fldoe.org/core/fileparse.php/7564/urlt/evaluationrubricscoringsheet.pdf. Acesso em: 08 nov. 2016.

${ }^{15}$ Disponível em http://www.fldoe.org/core/fileparse.php/7564/urlt/improvementplan.pdf. Acesso em: 08 nov. 2016.
} 
Quadro 1 - Componentes avaliados no Tópico Instrução do ExC3EL

\begin{tabular}{|c|c|c|c|c|}
\hline Componentes & Introdutória & Em desenvolvimento & Avançada & Exemplar \\
\hline $\begin{array}{l}\text { Letramento } \\
\text { informacional e } \\
\text { instrução baseada } \\
\text { em } \\
\text { questionamentos }\end{array}$ & $\begin{array}{l}\text { - O ensino de habilidades de } \\
\text { competência informacional não é } \\
\text { integrado ao programa educativo } \\
\text { da biblioteca. Não são usados } \\
\text { nem dados de desempenho dos } \\
\text { alunos nem dados obtidos através } \\
\text { de sistemas automatizados para se } \\
\text { planejar e modificar o programa } \\
\text { educativo da biblioteca. } \\
\text { - O ensino focado no } \\
\text { desenvolvimento de habilidades } \\
\text { de cidadania digital do aluno (ex: } \\
\text { localizar, avaliar e usar } \\
\text { informação de modo ético e } \\
\text { responsável) não está incluído no } \\
\text { programa educativo da biblioteca. }\end{array}$ & $\begin{array}{l}\text { - Habilidades padrão de } \\
\text { competência informacional são } \\
\text { ensinadas através do programa } \\
\text { educativo da biblioteca. } \\
\text { - Dados de sistemas automatizados } \\
\text { são utilizados para planejar o } \\
\text { programa educativo da biblioteca. } \\
\text { - O ensino focado no } \\
\text { desenvolvimento de habilidades de } \\
\text { cidadania digital do aluno (ex: } \\
\text { localizar, avaliar e usar informação } \\
\text { de modo ético e responsável) está } \\
\text { incluído no programa educativo da } \\
\text { biblioteca. }\end{array}$ & 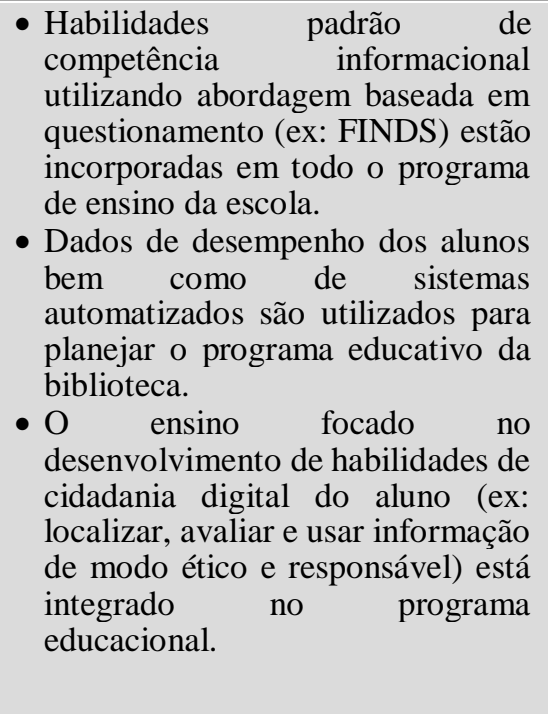 & $\begin{array}{l}\text { - Habilidades padrão de } \\
\text { competência informacional } \\
\text { utilizando abordagem baseada em } \\
\text { questionamento (ex: FINDS) estão } \\
\text { incorporadas sistematicamente em } \\
\text { todo o programa de ensino da } \\
\text { escola. } \\
\text { - Dados de desempenho dos alunos } \\
\text { bem como de sistemas } \\
\text { automatizados são utilizados para } \\
\text { planejar e modificar o programa } \\
\text { educativo da biblioteca. } \\
\text { - O ensino focado no } \\
\text { desenvolvimento de habilidades de } \\
\text { cidadania digital do aluno (ex: } \\
\text { localizar, avaliar e usar informação } \\
\text { de modo ético e responsável) está } \\
\text { integrado sistematicamente no } \\
\text { programa educacional. }\end{array}$ \\
\hline $\begin{array}{l}\text { Ensino de } \\
\text { habilidades de } \\
\text { transletramento } \\
\text { (transição digital e } \\
\text { domínio das } \\
\text { culturas da } \\
\text { informação) }\end{array}$ & $\begin{array}{l}\text { - Ensino das habilidades de } \\
\text { comunicação e colaboração } \\
\text { através de múltiplas plataformas } \\
\text { (ex: comunicação tradicional e } \\
\text { redes sociais) não se inclui no } \\
\text { programa educativo da biblioteca. } \\
\text { - Ensino das leis de direito autoral } \\
\text { e de propriedade intelectual (ex: } \\
\text { Creative Commons) não se inclui } \\
\text { no programa educativo da } \\
\text { biblioteca. } \\
\text { - Ensino incluindo segurança na } \\
\text { internet e pegadas digitais (ex: } \\
\text { ciberbullying) não é feito pelo } \\
\text { programa educativo da biblioteca. } \\
\text { - Ensino com maior ênfase e } \\
\text { consciência da comunicação } \\
\text { digital (ex: privacidade, } \\
\text { segurança, audiência) não se }\end{array}$ & $\begin{array}{l}\text { - Ensino das habilidades de } \\
\text { comunicação e colaboração através } \\
\text { de múltiplas plataformas (ex: } \\
\text { comunicação tradicional e redes } \\
\text { sociais) está incluído no programa } \\
\text { educativo da biblioteca. } \\
\text { - Ensino envolvendo as leis de } \\
\text { direito autoral e de propriedade } \\
\text { intelectual (ex: Creative } \\
\text { Commons) se inclui no programa } \\
\text { educativo da biblioteca. } \\
\text { - Ensino incluindo segurança na } \\
\text { internet e pegadas digitais (ex: } \\
\text { ciberbullying) é dado pelo } \\
\text { programa educativo da biblioteca. } \\
\text { - Ensino com maior ênfase e } \\
\text { consciência da comunicação digital } \\
\text { (ex: privacidade, segurança, }\end{array}$ & $\begin{array}{l}\text { - Ensino das habilidades de } \\
\text { comunicação e colaboração através } \\
\text { de múltiplas plataformas (ex: } \\
\text { comunicação tradicional e redes } \\
\text { sociais) está incorporado em todo o } \\
\text { programa de ensino da escola. } \\
\text { - Ensino envolvendo as leis de } \\
\text { direito autoral e de propriedade } \\
\text { intelectual (ex: Creative } \\
\text { Commons) está incorporado em } \\
\text { todo o programa de ensino da } \\
\text { escola. } \\
\text { - Ensino incluindo segurança na } \\
\text { internet e pegadas digitais (ex: } \\
\text { ciberbullying) é incorporado em } \\
\text { todo o programa de ensino da } \\
\text { escola. } \\
\text { - Ensino com maior ênfase e } \\
\text { consciência da comunicação digital }\end{array}$ & $\begin{array}{l}\text { - Ensino das habilidades de } \\
\text { comunicação e colaboração através } \\
\text { de múltiplas plataformas (ex: } \\
\text { comunicação tradicional e redes } \\
\text { sociais) está sistematicamente } \\
\text { incorporado em todo o programa } \\
\text { de ensino da escola. } \\
\text { - Ensino envolvendo as leis de } \\
\text { direito autoral e de propriedade } \\
\text { intelectual (ex: Creative } \\
\text { Commons) está sistematicamente } \\
\text { incorporado em todo o programa } \\
\text { de ensino da escola. } \\
\text { - Ensino incluindo segurança na } \\
\text { internet e pegadas digitais (ex: } \\
\text { ciberbullying) é sistematicamente } \\
\text { incorporado em todo o programa } \\
\text { de ensino da escola. }\end{array}$ \\
\hline
\end{tabular}

Bibl. Esc. em R., Ribeirão Preto, v. 5, n. 2, p. 1-20, 2017. 
Liderar, ensinar e apoiar: o papel e a expertise do bibliotecário escolar da Flórida para uma reflexão no contexto brasileiro

\begin{tabular}{|c|c|c|c|c|}
\hline Componentes & Introdutória & Em desenvolvimento & Avançada & Exemplar \\
\hline & $\begin{array}{l}\text { inclui no programa educativo da } \\
\text { biblioteca. }\end{array}$ & $\begin{array}{l}\text { audiência) se inclui no programa } \\
\text { educativo da biblioteca. }\end{array}$ & $\begin{array}{l}\text { (ex: privacidade, segurança, } \\
\text { audiência) se incorpora a todo o } \\
\text { programa de ensino da escola. }\end{array}$ & $\begin{array}{l}\text { - Ensino com maior ênfase e e } \\
\text { consciência da comunicação digital } \\
\text { (ex: privacidade, segurança, } \\
\text { audiência) se incorpora } \\
\text { sistematicamente a todo o } \\
\text { programa de ensino da escola. }\end{array}$ \\
\hline $\begin{array}{l}\text { Apreciação literária } \\
\text { e ensino baseado } \\
\text { em literatura }\end{array}$ & $\begin{array}{l}\text { - Apreciação, atividades e ensino } \\
\text { da literatura não estão integrados } \\
\text { ao programa educativo. } \\
\text { - Não há evidência de programas } \\
\text { baseados em literatura na } \\
\text { biblioteca. }\end{array}$ & $\begin{array}{l}\text { - Apreciação, atividades e ensino da } \\
\text { literatura estão integrados com o } \\
\text { programa educativo. } \\
\text { - O programa baseado em literatura } \\
\text { é planejado e executado e inclui } \\
\text { estratégias e habilidades de leitura } \\
\text { (ex: READS). }\end{array}$ & $\begin{array}{l}\text { - Apreciação, atividades e ensino da } \\
\text { literatura estão incorporados no } \\
\text { programa educativo. } \\
\text { - O programa baseado em literatura } \\
\text { é planejado e executado } \\
\text { oferecendo uma abordagem } \\
\text { unificada ao letramento e } \\
\text { reforçando estratégias e } \\
\text { habilidades de leitura (ex: } \\
\text { READS). }\end{array}$ & $\begin{array}{l}\text { - Apreciação, atividades e ensino da } \\
\text { literatura são sistematicamente } \\
\text { incorporados no programa } \\
\text { educativo. } \\
\text { - O programa baseado em literatura } \\
\text { é colaborativamente planejado e } \\
\text { executado oferecendo uma } \\
\text { abordagem unificada ao letramento } \\
\text { e reforçando estratégias e } \\
\text { habilidades de leitura (ex: } \\
\text { READS). }\end{array}$ \\
\hline Parceria no ensino & $\begin{array}{l}\text { - Não existe parceria de ensino } \\
\text { entre sala de aula e o programa da } \\
\text { biblioteca. } \\
\text { - O programa educativo da } \\
\text { biblioteca não inclui produção } \\
\text { dos alunos e professsores. } \\
\text { - Não existe colaboração entre o } \\
\text { programa da biblioteca e as áreas } \\
\text { do conhecimento ou as séries } \\
\text { escolares. }\end{array}$ & $\begin{array}{l}\text { - A parceria de ensino entre sala de } \\
\text { aula e o programa da biblioteca está } \\
\text { em desenvolvimento (existe } \\
\text { evidência limitada). } \\
\text { - O programa educativo da } \\
\text { biblioteca inclui produção dos } \\
\text { alunos através das habilidades de } \\
\text { leitura e pesquisa. } \\
\text { - Existe alguma colaboração entre o } \\
\text { programa da biblioteca e as áreas } \\
\text { do conhecimento ou séries } \\
\text { escolares através do } \\
\text { desenvolvimento, implementação e } \\
\text { análise de lições, unidades de } \\
\text { aprendizagem e projetos. }\end{array}$ & $\begin{array}{l}\text { - Existe parceria de ensino entre } \\
\text { algumas turmas (sala de aula) e o } \\
\text { programa da biblioteca. } \\
\text { - O programa educativo da } \\
\text { biblioteca inclui produção de } \\
\text { alunos e professores através da } \\
\text { aplicação de habilidades de leitura, } \\
\text { escrita pesquisa e comunicação } \\
\text { (ex: FINDS e READS). } \\
\text { - Existe colaboração entre o } \\
\text { programa da biblioteca e as áreas } \\
\text { do conhecimento ou séries } \\
\text { escolares através do do } \\
\text { desenvolvimento, implementaçãa e } \\
\text { análise de lições, unidades de } \\
\text { aprendizagem e projetos. }\end{array}$ & $\begin{array}{l}\text { - Existe parceria de ensino entre a } \\
\text { maioria das turmas (sala de aula) e } \\
\text { o programa da biblioteca. } \\
\text { - O programa educativo da } \\
\text { biblioteca promove a expressão } \\
\text { criativa e a produção de alunos e e } \\
\text { professores através da aplicação de } \\
\text { habilidades de leitura, escrita, } \\
\text { pesquisa e comunicação (ex: } \\
\text { FINDS e READS). } \\
\text { - Existe colaboração sistemática } \\
\text { entre o programa da biblioteca e as } \\
\text { áreas do conhecimento ou séries } \\
\text { escolares atrésés do } \\
\text { desenvolvimento, implementação e } \\
\text { análise de lições, unidades de } \\
\text { aprendizagem e projetos. }\end{array}$ \\
\hline
\end{tabular}

Bibl. Esc. em R., Ribeirão Preto, v. 5, n. 2, p. 1-20, 2017. 
o programa educativo por ela oferecido deve estar em consonância com o programa educativo de toda a escola, preferencialmente ele deve ser parte do programa da escola. Desse modo, na biblioteca escolar exemplar, encontraremos o ensino das habilidades de competência informacional; a instrução incluindo comunicação e colaboração em múltiplas plataformas, envolvendo ambientes digitais, leis de direito autoral e segurança na internet; a apreciação da literatura; a colaboração entre professor e biblioteca, com inclusive aulas e produção acontecendo no ambiente da biblioteca, como partes não somente do programa da biblioteca, mas sistematicamente incluídas no projeto pedagógico da escola.

Se o tópico instrução visava verificar o quanto a biblioteca é capaz de dar suporte às atividades de desenvolvimento da competência informacional dos alunos, o tópico apoio ao currículo (Quadro 2) verifica três componentes:

1. Promoção de leitura: aqui vista não somente como uma atividade que deva estar aliada às disciplinas, como antes, no tópico instrução, mas tamb[em ressaltando a importância da leitura de fruição ou leitura recreativa. O grande papel da biblioteca passa a ser dotar o indivíduo da capacidade de saber selecionar aquilo que lhe agrada. As bibliotecas exemplares serão aquelas que, além de conseguirem isso, participarem sistematicamente de programas de leitura oferecidos/patrocinados pelo estado, como aqueles já descritos nesse artigo, promovidos pela FAME: o SSYRA, o SSYRA Jr. e o Florida Teens Read.

2. Desenvolvimento profissional: o bibliotecário é não só o mediador do acesso à informação como também o mediador do acesso à tecnologia da informação. Portanto, pressupõe-se que uma biblioteca escolar em desenvolvimento procure oferecer aos professores o suporte necessário para que eles possam preparar aulas melhores - seja esse suporte informacional ou tecnológico. Nesse item, avalia-se o quanto o programa de biblioteca é capaz de oferecer (ou não) esse apoio.

3. Plano de desenvolvimento da escola: Talvez o que tenhamos no Brasil que mais proximamente reflita o plano de desenvolvimento da escola seja o projeto pedagógico (PP). De todo modo, o que se avalia nesse item é a inserção (ou não) da biblioteca nesse plano (projeto). Da biblioteca escolar no estágio introdutório, não espera-se que estaja incluída no plano da escola; quando está em desenvolvimento, já deve estar mencionada no plano; a biblioteca avançada não é apenas mencionada no plano, mas tem seu programa alinhado com a missão e com os objetivos de aprendizagem da escola; e a biblioteca exemplar é aquela em que o nível de colaboração é máximo: ela não é mencionada no plano, ela é integrada a ele, pois trabalha colaborativamente para que suas metas sejam alcançadas. 
Liderar, ensinar e apoiar: o papel e a expertise do bibliotecário escolar da Flórida para uma reflexão no contexto brasileiro

Quadro 2 - Componentes avaliados no Apoio ao currículo do ExC3EL

\begin{tabular}{|c|c|c|c|c|}
\hline Componentes & Introdutória & Em desenvolvimento & Avançada & Exemplar \\
\hline $\begin{array}{l}\text { Promoção e } \\
\text { orientação de } \\
\text { leitura }\end{array}$ & $\begin{array}{l}\text { - O programa da biblioteca não } \\
\text { promove atividades que } \\
\text { encoragem a leitura recreativa. } \\
\text { - O programa da biblioteca não } \\
\text { promove atividades de leitura } \\
\text { que foquem em habilidades de } \\
\text { escolha própria para suprir } \\
\text { tanto as necessidades } \\
\text { recreativas quanto as } \\
\text { escolares. } \\
\text { O programa da biblioteca não } \\
\text { promove um programa de } \\
\text { motivação de leitura. }\end{array}$ & $\begin{array}{l}\text { - O programa da biblioteca promove } \\
\text { algumas atividades de leitura (ex: } \\
\text { exibições, concursos, etc.) que } \\
\text { encorajam a leitura recreativa. } \\
\text { - O programa da biblioteca promove } \\
\text { algumas atividades de leitura } \\
\text { individuais ou com algumas turmas } \\
\text { focando em habilidades de escolha } \\
\text { para suprir as necessidades } \\
\text { recreativas ou escolares. } \\
\text { - O programa da biblioteca promove } \\
\text { um programa de motivação de } \\
\text { leitura limitado. }\end{array}$ & $\begin{array}{l}\text { - O programa da biblioteca inclui } \\
\text { atividades de promoção de leitura } \\
\text { (ex: exibições, concursos, } \\
\text { publicações eletrônicas e } \\
\text { impressas, etc.) que apoiam o } \\
\text { programa educativo da biblioteca } \\
\text { e que encorajam a leitura } \\
\text { recreativa. } \\
\text { - O programa da biblioteca } \\
\text { promove atividades de leitura } \\
\text { com grupos grandes, pequenos ou } \\
\text { individualmente focando em } \\
\text { habilidades de escolha própria } \\
\text { para suprir tanto as necessidades } \\
\text { recreativas quanto as escolares. } \\
\text { - O programa da biblioteca } \\
\text { promove um programa de } \\
\text { motivação de leitura (ex: FRA, } \\
\text { SSYRA, Florida Teens Read). }\end{array}$ & $\begin{array}{l}\text { - O programa da biblioteca é planejado } \\
\text { colaborativamente e inclui atividades de } \\
\text { promoção de leitura (ex: eventos, } \\
\text { exibições, concursos, publicações } \\
\text { eletrônicas e impressas, etc.) que apoiam } \\
\text { o programa educativo de toda a escola e } \\
\text { que encorajam a leitura recreativa. } \\
\text { - programa da biblioteca promove } \\
\text { atividades de leitura em áreas de } \\
\text { conteúdo com grupos grandes, pequenos } \\
\text { ou individualmente focando em } \\
\text { habilidades de escolha própria para } \\
\text { suprir tanto as necessidades recreativas } \\
\text { quanto as escolares. } \\
\text { - O programa da biblioteca promove } \\
\text { programas de motivação de leitura por } \\
\text { toda a escola (ex: FRA, SSYRA, Florida } \\
\text { Teens Read). }\end{array}$ \\
\hline $\begin{array}{l}\text { Desenvolvimento } \\
\text { profissional }\end{array}$ & $\begin{array}{l}\text { - Sessões de desenvolvimento } \\
\text { profissional não sáo facilitadas } \\
\text { através do programa da } \\
\text { biblioteca. } \\
\text { - Sessões de desenvolvimento } \\
\text { profissional náo são } \\
\text { oferecidas. }\end{array}$ & $\begin{array}{l}\text { - Sessões de desenvolvimento } \\
\text { profissional são facilitadas através } \\
\text { do programa da biblioteca e focam } \\
\text { em novas tecnologias e recursos de } \\
\text { bibliotecas emergentes. } \\
\text { - Desenvolvimento profissional é } \\
\text { oferecido em sessões face a face } \\
\text { (presenciais). }\end{array}$ & $\begin{array}{l}\text { - Sessões de desenvolvimento } \\
\text { profissional são facilitadas } \\
\text { através do programa da } \\
\text { biblioteca, incluindo novas } \\
\text { tecnologias e recursos de } \\
\text { bibliotecas, e estratégias de } \\
\text { ensino emergentes (ex: cidadania } \\
\text { digital, ferramentas interativas, } \\
\text { metodologias de ensino). } \\
\text { - Desenvolvimento profissional é } \\
\text { oferecido em sessões face a face } \\
\text { (presenciais) atilizando } \\
\text { ferramentas de apresentação } \\
\text { tecnológicas. }\end{array}$ & $\begin{array}{l}\text { - Sessões de desenvolvimento profissional } \\
\text { são facilitadas por toda a escola através } \\
\text { do programa da biblioteca, incluindo } \\
\text { novas tecnologias e recursos de } \\
\text { bibliotecas, estratégias de ensino } \\
\text { emergentes (ex: cidadania digital, } \\
\text { ferramentas interativas, metodologias de } \\
\text { ensino). } \\
\text { - Desenvolvimento profissional é } \\
\text { oferecido através de oportunidades } \\
\text { mistas de ensino (presenciais e a } \\
\text { distância, ex: webinars, podcasts). }\end{array}$ \\
\hline $\begin{array}{l}\text { Plano de } \\
\text { desenvolvimento da } \\
\text { escola }\end{array}$ & $\begin{array}{l}\text { - O programa da biblioteca não } \\
\text { é mencionado no Plano de } \\
\text { desenvolvimento da escola. }\end{array}$ & $\begin{array}{l}\text { - O programa da biblioteca é } \\
\text { mencionado no Plano de } \\
\text { desenvolvimento da escola. }\end{array}$ & $\begin{array}{l}\text { - O programa da biblioteca é } \\
\text { mencionado no Plano de } \\
\text { desenvolvimento da escola e está } \\
\text { alinhado com sua missão e seus } \\
\text { objetivos de aprendizagem. }\end{array}$ & $\begin{array}{l}\text { - O programa da biblioteca está integrado } \\
\text { ao Plano de desenvolvimento da escola e } \\
\text { alinhado com sua missão e seus } \\
\text { objetivos de aprendizagem. }\end{array}$ \\
\hline
\end{tabular}


O que os quadros 1 e 2 demonstram, por serem justamente os dois primeiros itens avaliados no programa de bibliotecas da Flórida, é que mesmo antes de se avaliar coleção, organização, espaço físico, equipe, orçamento e outros itens, antes de tudo, o que é analisado na biblioteca escola é seu programa educativo: instrução e apoio ao currículo. Estes são os primeiros itens a serem observados, os outros são aqueles que dão suporte para que esses - os objetivos primordiais de uma biblioteca escolar - aconteçam.

\section{Considerações finais}

O bibliotecário escolar deve ser um profissional capaz de liderar - propondo o trabalho colaborativo, apresentando inovações tecnológicas, garantindo o acesso à informação - de ensinar - habilidades de localização, avaliação e uso crítico da informação, bem como estratégias de pesquisa e de leitura - e de apoiar - a comjunidade escolar em suas atividades. Basta, para isso, uma formação em biblioteconomia, ou se faz necessária uma formação complementar na área de educação?

$\mathrm{Na}$ Flórida, o profissional é primeiro um educador para, depois, se tornar um bibliotecário. Será esse o melhor caminho?

A questão é tão capiciosa quanto “quem surgiu primeiro, o ovo ou a galinha?”. Muito óbvio que qualquer formação pedagógica auxilia um profissional a lidar com crianças e jovens. Tão óbvio quanto dizer que ler auxilia o bibliotecário a indicar livros. Nem por isso todo bom bibliotecário é - como deveria ser - um bom leitor. Ideal que todo bibliotecário escolar fosse um educador? Sem dúvida. Possível?

A lei 12.224/2010 (BRASIL, 2010), exige que até 2020 todas as escolas brasileiras possuam bibliotecas. No Brasil ideal, todas essas bibliotecas escolares possuiriam bibliotecários. No Brasil ideal, todos esses bibliotecários teriam especialização em biblioteconomia escolar que lhe garantiria essa formação adicional em tópicos como estudos sobre a infância; literatura infanto-juvenil; necessidades informacionais de crianças; necessidades informacionais de jovens; recursos informacionais para crianças e jovens; alfabetização e letramento; letramento/competência informacional; bibliotecas digitais; papel educacional do especialista em informação; entre outros. 
Liderar, ensinar e apoiar: o papel e a expertise do bibliotecário escolar da Flórida para uma reflexão no contexto brasileiro

O ideal hoje, no entanto, parece-nos distante da realidade. Dois longos caminhos precisam ser percorridos. O primeiro, de se demonstrar a importância do profissional bibliotecário nas bibliotecas escolares (sem ele, elas nada mais serão que uma sala de livros sem propósito nem programa) e de se garantir, também por lei, pelo menos um bibliotecário por biblioteca escolar. O segundo, de se colocar nas escolas brasileiras bibliotecários com formação adequada e dispostos a implantar Bibliotecas (com B maiúsculo) em todos os municípios deste nosso Brasil.

Quem disse que longos caminhos não são belos de serem trilhados?

\section{Referências}

AMERICAN LIBRARY ASSOCIATION. Information literacy competency standards for higher education. Chicago: ALA, 2000. Disponível em:

http://www.ala.org/acrl/sites/ala.org.acrl/files/content/standards/standards.pdf. Acesso em: 2 nov. 2016.

BRASIL. Lei 12.224, de 24 de maio de 2010. Dispõe sobre a universalização das bibliotecas nas instituições de ensino do país. Diário Oficial da União, Brasília, 25 maio 2010, p. 3.

EVERHART, N.; JOHNSTON, M. P. A proposed theory of school librarian leadership: a meta-ethnographic approach. School Library Research, v. 19, p. 1-30, 2016. Disponível em: <http://www.ala.org/aasl/sites/ala.org.aasl/files/ content/aaslpubsandjournals/slr/vol19/SLR_ProposedTheory_V19.pdf >. Acesso em: 2 nov. 2016.

EISENBERG, M. B. Information literacy: essential skills for the information age. DESIDOC Journal of Library \& Information Technology, v. 28, n. 2, p. 39-47, mar. 2008.

ExC3EL - Expectations for Collaboration, Collections, and Connections to Enhance Learning: a Program Evaluation Rubric. Ferramenta de avaliação das bibliotecas escolares da Flórida. [20--]Disponível em:

$\langle$ http://www.fldoe.org/core/fileparse.php/7564/urlt/evaluationrubric.pdf $>$. Acesso em: 2 nov. 2016.

GORDON, C. A. An emerging theory for evidence based information literacy instruction in school libraries, part 1: Building a foundation. In: MCINTOSH, J. Library and information science: parameters and perspectives. Apple Academic Press, 2011. p. 160-185.

MARDIS, M. A. The collection program in schools. 6. ed. Santa Barbara: Libraries Unlimited, Library and Information Science Text Series, 2016. 330p. 